\title{
Unity of the intellectual virtues
}

\author{
Alan T. Wilson ${ }^{1}$ (D) \\ Received: 15 July 2020 / Accepted: 19 May 2021 / Published online: 9 June 2021 \\ () The Author(s) 2021
}

\begin{abstract}
The idea that moral virtues form some sort of "unity" has received considerable attention from virtue theorists. In this paper, I argue that the possibility of unity among intellectual virtues has been wrongly overlooked. My approach has two main components. First, I work to distinguish the variety of different views that are available under the description of a unity thesis. I suggest that these views can be categorised depending on whether they are versions of standard unity or of strong unity. Standard unity claims that the possession of one virtue implies possession of all the others. Strong unity claims that the virtues are, in some sense, all the same thing. By exploring what these different versions of unity would look like when applied to intellectual virtues, I aim to provide a menu of options for future work in virtue epistemology. I then develop and defend one of these options in more detail, arguing that the initially less plausible strong unity has merit when applied to the intellectual sphere. In these two ways, I aim to show that the possibility of unity among the intellectual virtues is deserving of serious consideration.
\end{abstract}

Keywords Virtue epistemology · Intellectual virtues · Unity thesis · Virtue theory

\section{Introduction}

The idea that moral virtues form some sort of "unity" has received considerable attention from virtue theorists. My aim in this paper is to argue that theorists have wrongly overlooked the possibility of unity among the intellectual virtues. My approach has two main components. First, I will work to distinguish and categorize the variety of different views that are available under the description of a unity thesis. By exploring what these views look like when applied to intellectual virtues, it is possible to provide a menu of options for future work in virtue epistemology. Second, I will then seek to develop and defend one of these options in more detail.

Alan T. Wilson

alan.wilson@bristol.ac.uk

1 Department of Philosophy, University of Bristol, Cotham House, Bristol BS6 6LJ, UK 
In these ways, I aim to show that the possibility of unity among intellectual virtues is deserving of serious consideration.

\section{Preliminaries}

The different claims that theorists have had in mind when discussing the unity of virtues can be separated into two distinct camps. The claim most often discussed by contemporary theorists is that the possession of any one moral virtue implies possession of all of the others (see Annas, 2011; Badhwar, 1996; Hursthouse, 1999; Russell, 2009; Toner, 2014; Watson, 1984; Wolf, 2007). This understanding of unity is closely associated with Aristotle and is sometimes also referred to as the "reciprocity" (Annas, 2011, p. 85; Russell, 2009, p. 335) or "inseparability" (Devereux, 1992, p. 766) thesis. I will refer to claims that the virtues are unified in this sense as exemplifying a standard unity thesis.

A different sort of claim concerning unity was more commonly discussed among the ancients and instead proposes that the virtues are, in some sense, all the same thing (see Brickhouse \& Smith, 1997; Cooper, 1998; Devereux, 1992; Penner, 1973). I will refer to claims of this sort as exemplifying a strong unity thesis. A central aim for this paper is to distinguish different forms of both standard unity and strong unity and to explore what these views would look like when applied to intellectual virtues.

It is important to be clear on the concept of intellectual virtue that I am working with in this paper. Recent debates within virtue epistemology are complicated by the fact that theorists are working with two different conceptions of intellectual virtue (Battaly, 2015, Ch. 1-3). On an outcomes-based (or 'reliabilist') conception, intellectual virtues are those features of an agent that reliably produce epistemically valuable states, such as true belief or knowledge. On this conception, intellectual virtues might include skills or faculties (such as good eyesight or a reliable memory) in addition to character traits.

On a motivations-based (or 'responsibilist') conception, intellectual virtues are all character traits and all involve epistemically valuable motivations. To say that virtues are character traits is to say that they are dispositions to think, feel, act and be motivated in particular ways (Battaly, 2019, pp. 117-118). For example, the trait of honesty might be thought of as a disposition to avoid deception and to care about truth. It might also involve dispositions to feel shame about any past dishonesty and to feel disapproval in response to the dishonesty of others. The character traits typically identified as intellectual virtues by the responsibilist conception include inquisitiveness, open-mindedness and intellectual humility. I focus on this conception of intellectual virtues in this paper.

On this conception, virtues ought to be thought of as a matter of degree. For example, an agent need not be perfectly or ideally courageous in order to count as virtuously courageous. Instead, someone counts as possessing the relevant virtue as long as they are "virtuous enough" (Russell, 2009, pp. 112-117) or as long as their level of virtue is above a certain 'threshold'. Below that level, an agent will no longer count as possessing the relevant virtue, but they also may not yet count as 
possessing the corresponding vice. The discussion of standard unity in this paper will focus on whether possessing one virtue (to the level required for virtue status) implies the possession of all virtues (to the level required for virtue status).

Before continuing, it is worth asking why the possibility of unity among intellectual virtues has been overlooked. Contemporary theorists interested in the unity thesis have largely taken Aristotle as their starting point, and Aristotle's (1998, Bk VI) discussion of unity centrally focuses only on the moral virtues. ${ }^{1}$ This might explain the failure to consider the possibility of unity within other spheres. However, that possibility becomes more intriguing once we recognise that an alternative (responsibilist) conception of intellectual virtue is now widespread within virtue epistemology and that this conception has more in common with Aristotle's understanding of moral virtues than with his understanding of intellectual virtues.

A different reason why theorists have not considered unity of the intellectual virtues might simply be that the view is prima facie implausible. Contemporary theorists have been sceptical of the idea that moral virtues cannot be possessed in isolation from each other, or that moral virtues are, in some sense, all the same thing. Perhaps unity is even less plausible in the case of intellectual virtues. Why suppose that an inquisitive agent must also be intellectually humble and open-minded, or that inquisitiveness, humility, and open-mindedness are, in some sense, all the same thing? By exploring the idea of unity in the intellectual sphere, I aim to encourage the re-evaluation of an important possibility that has been overlooked within virtue theory.

\section{Standard unity of the virtues}

In this section, I will clarify the standard unity thesis by distinguishing different forms of the view. My aim is to set out several theoretical options and to provide an initial sense of the strengths and weaknesses of those options. By exploring what each form of standard unity would look like for intellectual virtues, and by considering whether the same initial strengths and weaknesses seem to apply, I aim to provide a clearer sense of the options within virtue epistemology.

\subsection{Varieties of standard unity}

When discussing the "unity thesis", contemporary theorists tend to focus on the claim that moral virtues are inseparable from one another. That is, they have focused on the idea that the possession of any one moral virtue implies or requires the possession of all the others. A representative summary of this view (without using the label 'standard unity') is presented by Badhwar (1996, p. 307) as follows:

\footnotetext{
${ }^{1}$ For Aristotle's views on practical wisdom and its relationship to other (lesser) intellectual virtues, see Hursthouse (2006).
} 
Standard Unity: One virtue implies all; hence the absence of even one virtue implies the absence of all. For example, if a person, $\mathrm{P}$, is generous she must also be just, courageous, kind, and temperate, and if she lacks even one of these virtues, she must also lack the rest.

Different theorists then provide different explanations for why standard unity holds. One possibility is that standard unity is explained by a form of strong unity to the effect that all virtues are identical. If generosity is identical to justice (and to courage, and to temperance, and so on), this would explain why it is impossible for an agent to possess generosity without at the same time possessing justice (and so on). This idea will be discussed in more detail in Sect. 4.

An alternative explanation for standard unity is that the virtues are connected to some third factor and it is this shared connection that ensures the inseparability of the virtues. This is the Aristotelian position on unity of the moral virtues. According to Aristotle (1998, Bk.VI), the possession of any moral virtue requires the possession of practical wisdom. This is what ensures that a virtue is an excellence and that it will not lead us astray. However, practical wisdom is itself an excellence that requires "a correct grasp of the ends of action", and "in order not to be mistaken about the ends of action one must have the virtues" (Russell, 2009, p. 336). Therefore, the possession of any one moral virtue requires the possession of practical wisdom, while practical wisdom requires possession of all the moral virtues. For this reason, it is not possible to possess any one moral virtue without also possessing the others. This is the Aristotelian explanation for standard unity.

There has been little in the way of enthusiastic support for standard unity in recent times. One of the main reasons for scepticism has been the basic point that there seem to be plenty of counterexamples. We can perhaps all think of acquaintances or figures from popular culture who we would describe as honest but who lack compassion, or who we would describe as courageous despite a lack of generosity. The possibility of providing such examples becomes even more pronounced once we include seemingly lesser candidate moral virtues, such as wit. Considerations of this sort led Bernard Williams (1985, p. 36) to describe the idea that someone can possess one virtue without possessing the others as "a platitude". If we agree, then we must reject standard unity.

Another reason for rejecting standard unity involves criticism of the underlying Aristotelian explanation. That explanation relies on the claim that every moral virtue requires practical wisdom, as well as the claim that practical wisdom requires an understanding of the proper ends of action across all areas of life. Both claims have been challenged. For example, Neera Badhwar (1996, p. 313) argues that "human understanding is not an all or nothing affair" and so we should not expect practical wisdom to necessarily extend over all areas of a person's life. To use Badhwar's example, an agent may well be practically wise in her performance as a judge, while nevertheless lacking practical wisdom in her performance as a parent. Badhwar takes this to show that the possession of compassion, say, in one area of life, only requires practical wisdom within that same area, and not practical wisdom more generally. If correct, this would raise questions about the Aristotelian explanation for standard unity, and so raise questions for standard unity itself. 
It is not my aim to evaluate each version of the unity thesis. Instead, highlighting common objections helps to explain why alternative versions of the thesis have been developed. Distinguishing those versions allows for a more complete understanding of the options when we turn to consider the possibility of unity in the intellectual sphere. With this in mind, I will now set out restricted versions of standard unity that have been proposed in response to the objections just mentioned.

One theorist who proposes a restricted form of standard unity is Badhwar, whose version of the unity thesis builds upon her discussion of the possible fragmentation of practical wisdom. While Badhwar rejects the Aristotelian assumption of the globality of practical wisdom, she does accept that the possession of a moral virtue in a particular domain of an agent's life requires practical wisdom within that domain. She also accepts that practical wisdom within a given domain requires the possession of all moral virtues within that domain. Badhwar (1996, p. 308) therefore proposes a domain-specific version of standard unity (and of the underlying Aristotelian explanation). This view, presented in 'The Limited Unity of Virtue', can be set out as follows:

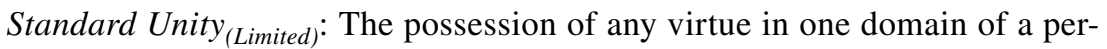
son's life implies the possession of the other virtues in that domain. However, the possession of a virtue in one domain does not imply the possession of that (or any other) virtue in any other domain.

This version of standard unity is an intermediate position and therefore faces challenges from two directions. On the one hand, those who favour standard unity will be unconvinced by the claim that an agent can be considered virtuously compassionate, say, in one area of her life, while lacking that very same virtue in other areas. An agent who is compassionate towards workmates, but who lacks compassion when interacting with her child, ought not to be judged virtuously compassionate in any sense (see Toner, 2014). On the other hand, those who are already sceptical of standard unity are likely to remain doubtful of the claim that an agent who is compassionate towards her children must also be honest in this same domain. While making the unity claim domain-specific allows Badhwar to accommodate some examples (such as the public figure who is courageous while campaigning, but who lacks temperance in her private life), standard unity (limited) $_{\text {. }}$ still faces significant challenges in this regard.

An additional challenge is associated with moving towards standard unity $_{\text {(limited) }}$. Doing so requires a method for determining the boundaries of different domains. Badhwar (1996, p. 316) is aware of this challenge and offers the following proposal:

I shall understand a domain to mean any area or realm of practical concern that can be psychologically isolated from other practical concerns, and that is important enough to justify the ascription of practical wisdom and virtue

Regardless of the merits of this proposal, it leaves some questions unanswered. For example, we need to know what is required for a candidate domain to count 
as "important enough". We also need to know how narrow in scope a domain can be while still being isolatable from other domains. Badhwar (1996, p. 316) allows for concerns relating to "physical risks" and "social risks" to be isolated from each other. What of more narrow concerns such as the risks associated with heights, or snakes, or terrorist attacks? It seems psychologically possible for these concerns to be isolated, and they are not obviously unimportant. To be com-

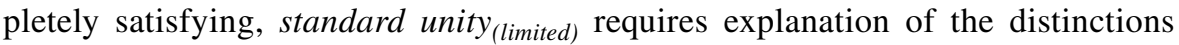
between domains and this explanation must be compatible with ascribing virtue within a single domain. Those who are concerned about the feasibility of dividing different areas of life into distinct domains are likely to be wary of standard unity $_{(\text {limited })}$.

This conclusion would not require abandonment of standard unity. While standard unity $_{(\text {limited) }}$ amends the view by making it domain-specific, an alternative proposal restricts standard unity in a different way:

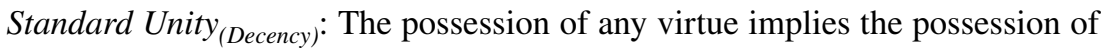
moral decency regarding the fields of the other virtues. However, it does not imply actual possession of those other virtues.

According to this proposal, it is not possible to possess a given virtue while at the same time being vicious regarding the fields of concern of the other virtues (see Russell, 2009, p. 357; Toner, 2014, pp. 210-211; Wolf, 2007). That is, it is not possible for an agent to possess the virtue of generosity (for example) while at the same time possessing the vices of cowardice, injustice, or cruelty. As noted above, someone can count as possessing a virtue as long as they are "virtuous enough". Below a certain level, an agent will no longer count as possessing the relevant virtue, but they also may not yet count as possessing the corresponding vice. Standard unity $_{(\text {decency) }}$ claims that an agent cannot meet the levels required for the possession of one virtue while at the same time falling viciously below the levels required for any of the others.

Retreating from standard unity to standard unity $_{(\text {decency) }}$ allows the idea of unity to be immune from certain counterexamples. For instance, this view can accept the possibility of agents who possess honesty without possessing compassion. The extent to which the view remains controversial will depend on the proposed levels of sufficiency for virtue and vice. If we think that agents only count as vicious (as opposed to simply non-virtuous) in extreme cases, then standard unity (decency) $_{\text {will }}$ not be all that surprising. If the threshold for vice possession is extreme, such that no one can plausibly be expected to satisfy the requirements for vice, then standard unity $_{(\text {decency) }}$ will be an uninteresting view. On the other hand, if the threshold for vice is more inclusive, such that most people can be expected to possess at least one vice, then standard unity $_{(\text {decency) }}$ will be more vulnerable to counterexamples. Whether or not this restricted view is implied by versions of strong unity (and by my own proposed version of intellectual strong unity) will be discussed below.

In recent work, Christopher Toner has appealed to the idea that there is a cardinal structure among the virtues in order to propose a different restricted version of standard unity. Put simply, cardinal understandings of the virtues propose that some virtues are more fundamental than others. Toner (2014, p. 225) builds on this idea 
to suggest that standard unity might apply only to the subset of fundamental moral virtues:

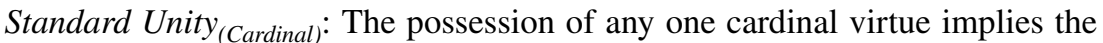
possession of all of the cardinal virtues. However, the possession of a noncardinal virtue does not imply the possession of other non-cardinal virtues.

Suppose we accept that courage, temperance and justice are the cardinal moral virtues. According to Toner's suggestion, it would not be possible to possess any of courage, temperance or justice without possessing all of them. It would be possible, however, to possess honesty without also possessing generosity. This view might allow a defender of the unity thesis to accommodate the sort of counterexamples that have led to the general scepticism regarding standard unity. However, this will only work if, in every case, the missing virtue is a non-cardinal virtue. As Toner acknowledges, standard unity $_{(\text {cardinal) }}$ also necessitates some explanation of which traits are the cardinal virtues.

It is worth mentioning one final proposal regarding standard unity. It would be possible to further restrict the unity claim by arguing that unity only applies to certain groupings or 'clusters' of virtues:

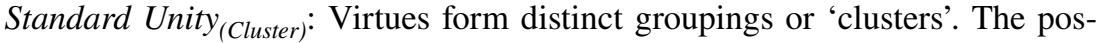
session of one virtue implies the possession of all other virtues within the same cluster, but does not imply the possession of any other virtues. ${ }^{2}$

On this view, possessing one virtue does not imply possessing all of the others. Instead, some virtues are connected in the sense that possessing one of them implies possession of the other virtues within the same cluster. Perhaps possessing virtuous compassion implies the possession of generosity (and vice versa), but does not imply the possession of honesty. Or possessing courage implies possessing temperance (and vice versa), but not humility.

One benefit of this view is that it avoids the references to "domains" and "cardinality" that were key elements of other restricted versions of standard unity. The view may also be less vulnerable to counterexamples. Any counterexample would need to focus on virtues that were proposed as being part of the same cluster. Of course, the plausibility of the view will depend on which virtues are claimed to be connected in this way and, indeed, on whether there are any virtues that are necessarily connected. Assessing this will require working through the various candidate virtues and attempting to determine, in each case, whether any two (or more) virtues really do imply each other.

A central aim for this paper is to distinguish the available options for theorists interested in unity among the virtues. I have set out the standard unity view and

\footnotetext{
${ }^{2}$ I am grateful to the anonymous reviewers for encouraging me to include a discussion of this additional form of standard unity.
} 
distinguished several restricted versions of that view. ${ }^{3}$ It is now possible to explore what standard unity would look like when applied to intellectual virtues.

\subsection{Applying standard unity to intellectual virtues}

A standard list of intellectual virtues will include traits such as inquisitiveness, open-mindedness and intellectual humility. If we accept this, then the implications of intellectual standard unity are clear. It implies that it is not possible to possess any one of these intellectually virtuous traits without possessing all of the others. What explanation could be provided for such a view? And is intellectual standard unity any more or less plausible than its moral counterpart?

One reason for thinking that intellectual standard unity is less plausible is that it lacks the underlying support of the Aristotelian explanation. Contemporary virtue theorists have been generally accepting of Aristotle's claim that moral virtues require practical wisdom (though see Driver, 2001 for one example of a dissenting view). While most have not gone on to endorse standard unity in an unrestricted form, the connection between moral virtue and practical wisdom at least provides an understandable motivation for that view. That same motivation will not exist in the case of intellectual virtues if intellectual virtues are not as closely connected with practical wisdom (though see Roberts \& Wood, 2007; and Baril, 2013 for related discussion). Quite apart from any worries about counterexamples, the plausibility of intellectual standard unity will suffer if we lack any initial motivation to accept the view.

And yet, it may be possible to find this motivation by thinking again about the connection between intellectual virtue and practical wisdom. Consider the standard explanation of why morally virtuous generosity requires practical wisdom. If generosity was simply a matter of regularly giving away your possessions to other people, then generosity would often lead an agent astray. Instead, virtuous generosity requires sensitivity to relevant features of the situation, such as whether handing over your possessions might harm the recipient (if the recipient is unable to properly manage those resources) or whether handing over your possessions might violate some other duty (if the possessions have already been promised to someone else). This need for sensitivity is what makes practical wisdom necessary for possession of morally virtuous generosity. It is worth considering whether this story also applies to intellectual virtues.

If inquisitiveness consisted solely of a tendency to ask questions, then inquisitiveness would be likely to often lead an agent astray. Instead, virtuous inquisitiveness requires a sensitivity to the situation, so that the inquisitive agent can ask the right

\footnotetext{
3 One restricted version that I have not discussed is the idea that standard unity holds only for perfect or ideal virtue. Perhaps in order to be perfectly compassionate one must also be perfectly just, courageous, and so on. Such a view might be more resistant to the sort of counterexamples considered above. I agree with Russell (2009, p. 363) that, even if true, such a view would be somewhat uninteresting, given that perfectly virtuous (human) agents are "surely only mythical creatures".
} 
questions, on the right occasions, and of the right people. Given this, we have the same reason for thinking that practical wisdom will be required here as we do in the case of generosity. And this similarity also applies to other commonly accepted intellectual virtues. Intellectual courage requires more than simply always standing your ground in defence of your beliefs. Instead, an intellectually courageous agent is responsive to the evidence and will alter her behaviour accordingly. The need for practical wisdom is as strong here as in the moral case. If this is correct, then intellectual standard unity could be motivated by the same Aristotelian explanation as in the moral sphere.

However, even if such a motivation exists, intellectual standard unity will also suffer from the same prima facie challenges. Most obvious is the possibility of counterexamples. Just as we can imagine agents who are honest while lacking compassion, so too we can imagine agents who are inquisitive while lacking intellectual humility. A journalist might be highly motivated to seek out important information, and be exceptionally skilled at asking the right questions, while at the same time being disposed to overestimate her own cognitive strengths. To the extent that such examples seem possible, the idea of intellectual standard unity will face the same prima facie objections as does the idea of unity in the moral sphere.

Restricted versions of the standard view also face the same challenges when applied to intellectual virtues. For example, we saw above that standard unity (limited) $_{\text {(n) }}$ faces both the challenge of dealing with possible counterexamples and the challenge of successfully dividing different areas of life into distinct "domains". These challenges will remain when standard unity $_{(\text {limited })}$ is applied to intellectual virtues. Similarly, we saw that standard unity ${ }_{(\text {decency) }}$ faces a specific challenge concerning where to set the threshold below which an agent can be considered vicious. If the threshold is extreme, then the view risks being uninteresting. If the threshold is more inclusive, then the view risks facing damaging counterexamples. Defenders of the view in the moral sphere therefore face the challenge of determining the relevant threshold and this same challenge will affect the view when applied to the intellectual sphere.

What of the possibility that intellectual virtues form distinct groupings, as is sug-

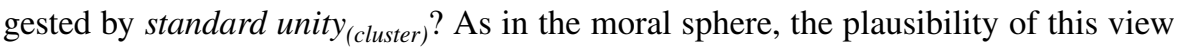
will depend on which intellectual virtues are proposed as forming a cluster. Recent work suggests some possibilities in this regard. For example, Heather Battaly (2020) argues for a connection between the vices of closed-mindedness and arrogance that might suggest a related connection between the intellectual virtues of open-mindedness and intellectual humility. However, Battaly does not go so far as to argue that these traits necessarily go together. Battaly (2017) has also argued for significant connections between the virtues of intellectual perseverance, courage and selfcontrol. As in the moral sphere, determining the plausibility of intellectual standard unity $_{(\text {cluster })}$ will require working through different proposed combinations of virtues, determining whether there is any connection and, if so, determining whether that connection is one of necessity or mere probability.

A supporter of intellectual standard unity therefore faces the same prima facie challenges and tasks as their moral counterpart. This alone is of some interest. The very possibility of the unity of intellectual virtues has been overlooked, and so it is somewhat surprising that the view may be no worse off than its moral counterpart. 
However, to the extent that theorists have been sceptical of standard unity, it appears that they have equal reason to be sceptical of intellectual standard unity. Later, I will consider whether my own preferred version of intellectual strong unity implies any version of intellectual standard unity and discuss whether this renders the proposal untenable.

\section{Strong unity of the virtues}

This section continues with the central task of distinguishing available options by exploring the idea of strong unity among the virtues. Again, my aim is to highlight different options and survey the initial strengths and weaknesses of those options.

\subsection{Varieties of strong unity}

The idea that virtues are, in some sense, all the same thing has received considerably less attention among contemporary theorists than has standard unity. The most influential discussion of strong unity occurs in Plato's Protagoras. Early in this discussion (Plato, 1955, p. 329c6-d1), the character Socrates distinguishes three different positions for Protagoras to choose from. First, Socrates asks:

whether virtue is one whole, of which justice and temperance and holiness are parts; or whether all these are only the names of one and the same thing

The first option (that the individual virtues are parts of a whole) also comes in two forms (Plato, 1955, p. 329d4-8):

And are they parts... in the same sense in which mouth, nose, and eyes, and ears, are parts of a face; or are they like the parts of gold, which differ from the whole and from one another only in being larger or smaller?

These distinctions present Protagoras (and the reader) with three options:

1. The virtues are identical, and virtue terms are just different names for one and the same thing.

2. The virtues are parts of one thing, analogous to the parts of gold.

3. The virtues are parts of one thing, analogous to the parts of a face.

Protagoras endorses the third option, and this view can be seen to make the weakest claim to unity out of the three options. First, if the analogy to the parts of a face is to be taken seriously, then this view is not a form of standard unity (as the possession of one part does not imply possession of the others). Second, there is no real sense in which different parts of a face are all "the same thing", as would be required for strong unity. Of course, they are the same in the minimal sense that they can all be described as "part of a face". But this seems too weak to constitute a claim to unity. I focus on the two stronger claims in what follows. 
Given that Socrates presents these three options, and that he clearly disagrees with Protagoras, we might assume that Socrates endorses either 1 or 2. However, theorists are (unsurprisingly) divided over Socrates's position. Some have argued that Socrates accepts no form of strong unity and only accepts standard unity. Gregory Vlastos (1972) argues that this is the only way to make Socrates's position in Protagoras consistent with his statements in other dialogues. Daniel Devereux (1992), on the other hand, argues that there is no consistent position from Socrates in these early dialogues and that it is a mistake to attempt to generate one. Thankfully, my aim is not to uncover Socrates's own position. Instead, I will use interpretations of Socrates as favouring either 1 or 2 in order to explain two distinct versions of strong unity.

The first version of strong unity corresponds to Socrates's option 1 and can be set out as follows:

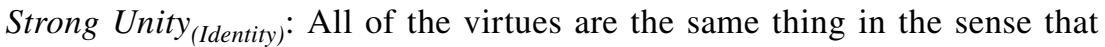
they are identical. On this view, courage is identical to justice, and to temperance, and to compassion, and so on.

This view is attributed to Socrates by Terry Penner. Penner (1973) argues that the most straightforward reading of Socrates in Protagoras implies the acceptance of identity among the virtues. The version of strong unity $_{(\text {identity) }}$ that Penner ascribes to Socrates is that all virtues consist of knowledge. Of course, not all knowledge is identical. Knowledge of when Protagoras was written is not identical to knowledge of who won the Super Bowl in 2021. To make an identity claim, we must suppose that the virtues are constituted by the same knowledge. One suggestion is that the virtues all consist of the knowledge of good and evil. This possibility is considered by Socrates in, for example, Plato's Laches (1997, pp. 198a-199e). On this view, courage $=$ knowledge of good and evil; temperance $=$ knowledge of good and evil; justice $=$ knowledge of good and evil; and so on. This would mean that courage $=$ temperance $=$ justice, and so would be a version of strong $_{\text {unity }}$ (identity) $_{\text {. }}$

The relationship between strong unity $_{(\text {identity })}$ and standard unity is straightforward in that the former implies the latter. If all virtues are identical, then the possession

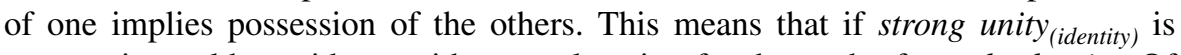
correct, it would provide us with an explanation for the truth of standard unity. Of course, it also means that strong unity $_{(\text {identity) }}$ suffers from the same challenges facing the standard view. If we accept the possibility of someone possessing one virtue without possessing the others, then we need to reject strong unity (identity). .

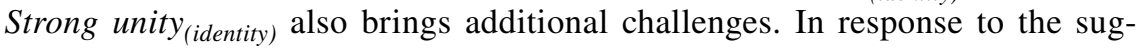
gestion that all moral virtues amount to the same thing, and that this one thing is benevolence, Hume is reported (Fieser, 1998, p. 298) to have responded:

Were Benevolence the only Virtue, no Characters cou'd be mixt, but wou'd depend entirely on their Degrees of Benevolence.

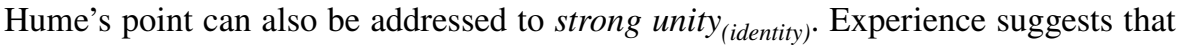
virtuous (and vicious) people differ in the traits that they possess and not just in the degree to which they possess the very same trait. Experience also suggests that 
people develop individual virtues differently and not all at the same time. An agent on the path to virtue may develop her courage before her generosity, or her honesty before her compassion. We would not expect these virtues to (always) appear all at once, and this fact is difficult to reconcile with the claim that the virtues are identical. Such challenges need to be faced by any theorist who endorses the form of strong unity corresponding to Socrates's option 1 in Protagoras. This might explain why contemporary theorists have been unwilling to endorse that view.

What about the version of strong unity that is suggested by Socrates's option 2? This version can be set out as follows:

Strong Unity (Substance) : All of the virtues are the same thing in the sense that they are parts or applications of the same thing. On this view, courage, justice, temperance, and so on, are parts or applications of the same thing.

For this view to differ from the weaker view that is suggested by the "face" analogy, it is important that the virtues are the "same thing" in some meaningful sense. One possibility is the view attributed to Socrates by Brickhouse and Smith (1997, pp. 321-324). They appeal to the idea that a discipline can have various applications. They use as an example the discipline of triangulation, and the applications of this discipline in surveying and in coastal navigation. According to Brickhouse and Smith, surveying and coastal navigation are both applications of the same discipline of triangulation, but they can be distinguished by appeal to their different contexts of application. Analogously, Brickhouse and Smith (1997, p. 322) suggest a view on which all virtues consist of the same knowledge (of good and evil), but can be distinguished by their different contexts of application:

For instance, justice may be the application of the knowledge of good and evil that results in benefit to others. Piety may be the application of the knowledge of good and evil that aids the gods in benefiting others.

Socrates's gold analogy is thus understood such that the equivalent to "gold" is "knowledge of good and evil". All the virtues can be described as consisting of this same knowledge. The equivalent to the differences in terms of being "larger or smaller" is the differences in the scope of application. This allows us to distinguish different applications of the same knowledge using different virtue terms.

Brickhouse and Smith then argue that this version of (what I am calling)

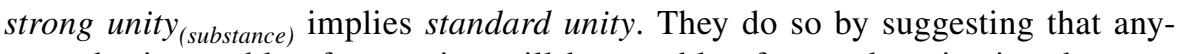
one who is capable of surveying will be capable of coastal navigation, because both involve applying the very same discipline of triangulation, albeit in different ways. Analogously, anyone who is pious will also be just, as these virtues involve applying the very same knowledge (of good and evil) in different contexts. If this is correct, then the version of strong unity $_{(\text {substance) }}$ that Brickhouse and Smith ascribe to Socrates also implies standard unity.

A different version of strong unity $_{(\text {substance) }}$ would instead claim that the virtues are distinct parts of the same knowledge. If overall virtue is understood as the knowledge of good and evil, then individual virtues could be thought of as distinct parts of that knowledge. For example, courage might be the knowledge of 
good and evil concerning what is to be feared, justice might be the knowledge of good and evil concerning what is owed, and so on. On this view, virtues will be part of the same overall knowledge, but they will be distinguishable in terms of their specific content. If it is possible to have part of the knowledge of good and evil without having all of it, then this alternative version of strong unity (substance) $_{\text {(n) }}$ does not imply standard unity.

Indeed, Brickhouse and Smith (1997, pp. 320-321) consider this alternative view but reject it as an interpretation of Socrates in Protagoras. The problem, according to Brickhouse and Smith, is that this version does not imply standard unity and they believe that Socrates did accept standard unity. However, the alternative version is worth mentioning here, given my broader aim of identifying the available options, rather than providing an interpretation of Socrates. It reveals the possibility of versions of strong unity $_{(\text {substance) }}$ that do not imply standard unity.

\subsection{Applying strong unity to intellectual virtues}

I will be proposing a version of intellectual strong unity $_{(\text {substance) }}$ in the next section.

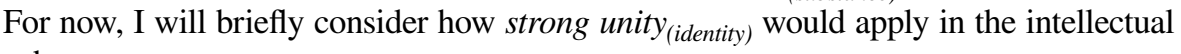
sphere.

If strong unity $_{\text {(identity) }}$ in the moral sphere claims that traits like courage, justice and temperance are identical, then strong unity $_{(\text {identity) }}$ in the intellectual sphere will claim that traits like inquisitiveness, open-mindedness and intellectual humility are identical. This would mean not only that whenever an agent possesses inquisitiveness, she must also possess open-mindedness and intellectual humility, but also that the agent's inquisitiveness consists of the very same thing as her open-mindedness and humility. As in the moral sphere, this view will imply standard unity and so will suffer from the same problematic counterexamples. If someone can possess inquisitiveness without possessing intellectual humility, this rules out intellectual strong unity $_{\text {(identity). }}$.

Intellectual strong unity $_{\text {(identity) }}$ also suffers from the related problem of suggesting an implausible account of virtue development. While it might be possible for someone to develop inquisitiveness, open-mindedness and intellectual humility all at once, it is not plausible to suggest that this must always happen. An agent on the path to virtue might find that inquisitiveness comes more naturally to her than does humility, such that development of the former is easier than development of the latter. This possibility would need to be denied by anyone who endorses the identity view for intellectual virtues. Intellectual strong unity $_{(\text {identity) }}$ therefore faces serious challenges.

The aim of this paper is to encourage discussion of the overlooked possibility of unity among intellectual virtues. Distinguishing the different versions of unity that are available is an important step in achieving that aim. If any one of these options is plausible, this would support the claim that unity in the intellectual sphere is worthy of serious consideration. In what remains, I want to take one additional step by developing a specific version of intellectual strong unity. It is hoped that this will provide further impetus for future work on this topic. 


\section{Supporting intellectual strong unity}

One version of strong unity $_{(\text {substance })}$ that was considered for the moral sphere stated that moral virtues are all the same thing in the sense that they are all parts or applications of the same knowledge. The version of strong unity (substance) $_{\text {that I want to }}$ now suggest for the intellectual sphere states that intellectual virtues are all the same thing in the sense that they are all parts or applications of the same virtue-the love of wisdom.

The character trait that I mean to identify by the term "love of wisdom" is familiar from standard lists of intellectual virtues, although it is sometimes referred to using different names. One of the most thorough treatments of this trait is provided by Roberts and Wood (2007, Ch. 6), who use the term "love of knowledge" (see also Baehr, 2011, p. 94). Agents who possess (what I am calling) love of wisdom are disposed to want to uncover important truths and to gain an understanding of important subject matters. Agents with an intellectually virtuous love of wisdom are also generally reliable in achieving these epistemically valuable states. ${ }^{4}$

The aim of referring to this virtue as love of wisdom is to emphasise that an agent who possesses this trait is not solely focused on propositional knowledge. While propositional knowledge will be of interest, the lover of wisdom will also be motivated by the pursuit of knowledge-how, as well as other epistemically valuable states such as true belief and understanding. While Roberts and Wood acknowledge this, it risks being overlooked when referring to the trait as love of knowledge. I instead use "wisdom" as a catch-all for the variety of epistemically valuable states that are pursued by an agent who possesses the virtue. ${ }^{5}$ The aim of referring to this virtue as love of wisdom is to emphasise the important motivational aspect of the trait. Having a love of wisdom is not primarily a matter of possessing wisdom (although this will tend to follow), but of being positively disposed towards it.

Many virtue theorists acknowledge the virtue status of what I am referring to as love of wisdom. Where my proposal differs is the suggestion that all intellectual virtues are unified in the sense of being part of this one virtue. Love of wisdom is not simply another virtue on the list of intellectual virtues. Instead, all of the "other" intellectual virtues are parts of this one, more fundamental, virtue. That is, the dispositions that constitute each of the more specific intellectual virtues are simply a subset of the dispositions that make up the more fundamental virtue of love of wisdom. ${ }^{6}$

But how plausible is this version of intellectual strong unity $_{\text {(substance) }}$ ? I will provide support for the proposal in two ways. First, by demonstrating that it is plausible

\footnotetext{
4 The inclusion of a "success component" is common among responsibilist virtue theorists (e.g. Zagzebski, 1996, Part II, Section 4).

${ }^{5}$ Use of the term wisdom does risk confusion if it is assumed to be referring to Aristotelian notions of practical or theoretical wisdom. To be clear, I am not intending to follow an Aristotelian usage of "wisdom" here.

6 The position of Roberts and Wood on this issue is complex. On the one hand, they explicitly rule out the proposal that I am making here (2007, p. 73). However, they also suggest in some places (e.g. 2007, p. 206) that love of knowledge might be a particularly important virtue.
} 
to understand widely accepted intellectual virtues as being part of the love of wisdom. Second, by responding to the possible objection that, even if the proposal is correct, it amounts only to an uninteresting form of unity, more akin to the "face" analogy in Protagoras.

Consider first the virtue of inquisitiveness. This virtue involves a disposition to ask questions and to engage in inquiry, and agents who possess the virtue will generally be successful in their pursuit of such inquiries. However, not just any tendency to ask questions counts as an intellectually virtuous form of inquisitiveness. The scientist whose tendency to ask questions is motivated solely by a desire for fame is not thereby intellectually virtuous. The philosopher who is disposed to ask questions of guest speakers out of a desire to humiliate them is not thereby intellectually virtuous. Instead, intellectually virtuous inquisitiveness must be a manifestation of a fundamental love of wisdom - a robust multi-track disposition in favour of epistemically valuable states. Indeed, intellectually virtuous inquisitiveness just is a restricted form of love of wisdom. It consists of the love of wisdom manifest in a tendency to ask questions and engage in inquiry. Anyone who possesses intellectually virtuous inquisitiveness thereby possesses part of the more fundamental virtue of love of wisdom.

Other intellectual virtues can also be viewed as part of the love of wisdom. The virtue of intellectual courage, according to Zagzebski (1996, p. 269), involves aiming to "defend one's belief or a line of inquiry when one has good reason to be confident that it is on the right track, and to fearlessly answer objections from others in order to ultimately get knowledge." Of course, someone might have the tendency to never back down from objections due to some other motivation, such as a motivation to save face or to appear impressive. As the quote from Zagzebski suggests, this tendency would not constitute an intellectual virtue. Instead, the dispositions that constitute virtuous intellectual courage must ultimately be grounded in a love of epistemically valuable states, like knowledge. Intellectual courage just is the love of wisdom, albeit a restricted form of that more general trait, manifest in the specific context of responding to challenges.

A final example adds further support. The virtue of open-mindedness plausibly involves a willingness to actively consider viewpoints that are different from our own, and to engage in respectful discussion with those who disagree with us. As with the other traits mentioned here, open-mindedness could be grounded in several different motivations. A philosopher might engage in respectful debate with others because she views this as a strategy for being well-liked in her department, and she might actively consider opposing viewpoints only when attempting to satisfy the demands of reviewers. Such an agent would not thereby possess open-mindedness as an intellectual virtue. Instead, this virtue requires a positive motivation for epistemically valuable states. The agent is disposed to consider opposing viewpoints and to engage in respectful discussion as a means to uncovering or deepening their understanding. In fact, open-mindedness (as an intellectual virtue) just is a part of love of wisdom. It is love of wisdom manifest in the specific circumstances of interacting with new or opposing ideas. To the extent that an agent manifests intellectually virtuous open-mindedness, she thereby manifests a love of wisdom. 
One way of putting pressure on these examples would be to argue that it is possible to lack one of the more specific virtues without this revealing any lack of the more fundamental virtue of love of wisdom. This would suggest that the specific virtue ought not to be thought of as simply part of love of wisdom. For example, it might be claimed that someone can demonstrate a lack of courage when backing down in the face of overwhelming risk, without this revealing any lack in their love of wisdom. Or it might be suggested that someone can lack virtuous open-mindedness due to being too open-minded, again without this demonstrating any lack in their love of wisdom. If so, this would suggest that these traits are not best thought of as being simply a part of love of wisdom.

In response to this worry, it is important to emphasise that love of wisdom is being conceived of as an intellectual virtue on this proposal, and not merely as a (shared) motivation. Consider again the idea that an excess level of open-mindedness can take someone beyond the bounds of virtue, rendering their trait not virtuous open-mindedness but rather intellectual naiveté. Such a person might care very much about achieving wisdom, in the sense that they are strongly motivated by this. But this would not show that they aren't lacking in love of wisdom as a virtue. To the extent we think that their level of open-mindedness has become non-virtuous, we will have the same reason to doubt the virtuousness of their love of wisdom. The same is true in the case of courage. Someone who backs down in the face of overwhelming risk does not necessarily reveal a lack of love of wisdom. But at the same time, it is also not obvious that they would be revealing a lack of virtuous courage. And, again, if we alter the case so that it does cast doubt on their virtuous courage, we will similarly have reason to doubt the virtuousness of their love of wisdom.

Of course, these examples have been necessarily brief. In order to fully assess the plausibility of this version of intellectual strong unity $_{(\text {substance) }}$ it would be necessary to address additional candidate intellectual virtues and to explore whether it is plausible to conceive of them as being part of a more fundamental love of wisdom. A central aim of this paper is to encourage such future work, alongside a broader reassessment of the overlooked possibility of unity among the intellectual virtues. However, the possibility of viewing traits as seemingly distinct as inquisitiveness, intellectual courage and open-mindedness as parts of the love of wisdom provides support for the proposed view. This, in turn, provides support for the claim that the unity of intellectual virtues is worthy of serious consideration.

A different worry for my proposal would be that, even if it is plausible, it is not really an interesting form of the unity thesis. Referring back to the options provided by Socrates, it might be thought that this proposal more closely resembles the "face" analogy than the "gold" analogy, and so is not making a unity claim in any interesting sense. There is good reason to reject this worry. First, as with the gold example, the proposal here is that all (intellectual) virtues are different parts of the same one thing. The equivalent to gold is the love of wisdom, and this love of wisdom runs through all of the more specific intellectual virtues. Unlike with the parts of a face, there is nothing more to the specific intellectual virtues than the love of wisdom, albeit manifest in particular, restricted, ways. The proposal therefore ought to be considered a version of strong unity $_{(\text {substance })}$ as set out above. 
A second reason for thinking that the proposal constitutes an interesting form of unity can be found by examining whether the proposal (unlike the "face" analogy) implies any form of standard unity.

The proposed version of strong unity $_{(\text {substance })}$ implies neither standard unity nor

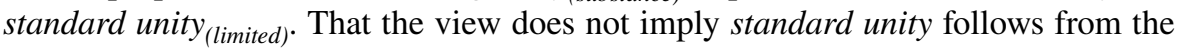
fact that an agent might possess one part of love of wisdom without thereby possessing all parts. An agent might be disposed to manifest her motivation for epistemically valuable states through the asking of questions, and yet not be similarly disposed to manifest this motivation by facing down challenges. Such an agent would possess love of wisdom manifest as inquisitiveness, but not yet possess love of wisdom manifest as intellectual courage. For this reason, the proposal should be viewed as a version of strong unity $_{(\text {substance })}$ that does not imply standard unity. The proposal also makes no mention of the different "domains" of life. For this reason, the proposed version of strong unity $_{(\text {substance) }}$ will not imply standard unity (limited) $^{\text {. }}$

Does the proposal imply any other form of the standard view? Most interesting

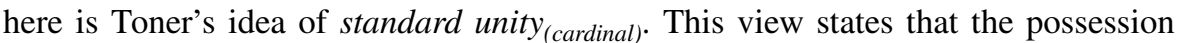
of any one cardinal virtue implies the possession of all, while the possession of a non-cardinal virtue does not imply the possession of any other non-cardinal virtues. On the proposed version of strong unity $_{(\text {substance) }}$, all intellectual virtues are part of the love of wisdom. This appeal to a virtue that is more fundamental than the others shares similarities with the idea of cardinality. Indeed, the proposed version of strong unity (substance) is equivalent to a view on which there is only one cardinal intellectual virtue: the love of wisdom. If this is correct, then the proposal has the implication that standard unity (cardinal) $_{\text {is }}$ true for intellectual virtues. Love of wisdom is the only cardinal (intellectual) virtue, and so the possession of any one cardinal (intellectual) virtue implies the possession of all cardinal (intellectual) virtues. And, as mentioned above, the possession of a non-cardinal virtue, such as inquisitiveness, will not imply the possession of other non-cardinal virtues. The proposal therefore implies at least one form of standard unity.

It is less clear whether the proposal implies another form of the standard view that was discussed above: standard unity $_{(\text {decency) }}$. This will depend on where we set the threshold for vice possession, and I am not aiming to address that question here. However, on the proposed view, the possession of any intellectual virtue will require the possession of at least part of the love of wisdom. If we think that this is incompatible with being properly intellectually vicious (although perhaps compatible with a lack of virtue), then the proposed form of intellectual strong unity (substance) $_{\text {would }}$ also imply intellectual standard unity ${ }_{(\text {decency) }}$.

In this section, I have developed a version of intellectual strong unity (substance) $_{\text {. If }}$ this proposal is correct, then not only will strong unity $_{(\text {substance) }}$ be true in the intellectual sphere, but also standard unity (cardinal) and perhaps standard unity $_{(\text {decency) }}$. The availability of such a view provides additional support for the claim that unity of the intellectual virtues is deserving of serious consideration. 


\section{Implications}

Virtue epistemologists have overlooked the possibility of unity among the intellectual virtues. By working to highlight the great variety of options that are available under the description of a unity thesis, I hope to have shown that this is, in fact, a promising and important topic for future work. Before concluding, I want to briefly highlight some of the implications that would follow from accepting a unity thesis for intellectual virtues.

Different versions of standard unity and strong unity will have different implications. For now, we can focus on the version of intellectual strong unity (substance) that was developed in Sect. 5. It might be thought that, even if true, this proposal will have few implications. Many theorists already accept that intellectual virtues require a shared motivation for valuable epistemic states, or "cognitive contact with reality" (Zagzebski, 1996, pp. 131-132). Does conceiving of the intellectual virtues as part of one fundamental virtue have implications that are not shared by this more familiar idea? If not, this unity thesis might be deemed as having little broader significance for virtue epistemology.

A first implication of strong unity $_{(\text {substance) }}$ is at the level of virtue theory. On the more familiar approach, intellectual virtues share a common underlying motivation (or motivational disposition) in favour of valuable epistemic states. On the unity view, the connection between virtues is deeper than this. Each of the more specific virtues consists of a subset of the dispositions that constitute the fundamental virtue of love of wisdom. Together, they form this one virtue. This suggests that, when aiming to provide an account of any given virtue, we should be trying to identify the specific, restricted way in which that virtue is a manifestation of love of wisdom.

This different way of approaching virtue theory opens up possibilities for future work. In particular, it may help to reveal additional connections between specific virtues (or groups of virtues). If we begin by first determining the dispositions that are constitutive of love of wisdom, and then seek to map which subset of these dispositions is manifest in each of the more specific virtues, this can help us to identify areas of overlap that go beyond one shared motivation. Conceptualising the more specific virtues as forming different parts of one fundamental virtue helps us to better situate those virtues in relation to each other, and to identify which virtues are more or less closely related.

This also applies to the emerging field of vice epistemology. If all intellectual virtues are part of the love of wisdom, then it will be important to reflect on how specific intellectual vices manifest a problematic failing of love of wisdom. Strong unity $_{(\text {substance) }}$ therefore provides an alternative starting point for future investigations into the nature of candidate intellectual virtues and vices.

Intellectual strong unity $_{(\text {substance) }}$ also has practical implications. In particular, it has implications for those interested in how best to develop virtuous traits, either in themselves or in others. The process of intellectual virtue development ought not to be conceived of as working through a laundry list of individual and unrelated traits. Instead, the proposed view suggests that the most effective method 
will be to focus on the fundamental virtue of love of wisdom. If an agent can successfully cultivate any aspect of the love of wisdom, then subsequent developments ought to come more easily. This will simply involve making agents familiar with the different contexts in which they ought to manifest their already-present love of wisdom. If the proposed version of intellectual strong unity (substance) $_{\text {is }}$ correct, then it will be important for future work on virtue development and virtue education to focus on how best to cultivate a virtuous love of wisdom, as opposed to merely educating for familiarity with virtue concepts or for competence regarding particular cognitive skills. In these ways, the acceptance of a unity thesis would have implications for how best to approach future work in virtue epistemology.

\section{Conclusion}

In this paper, I have sought to encourage future work on the idea of unity among intellectual virtues. My approach has been to distinguish the variety of options that are available under the description of a unity thesis and to then develop one of those options in more detail. In these two ways, I hope to have shown that the possibility of unity among the intellectual virtues is deserving of serious consideration.

Acknowledgements For comments and feedback on earlier versions of this paper, I am grateful to Christian Miller and members of the Work in Progress group at Wake Forest University, as well as to audiences at Oklahoma, Glasgow and Edinburgh. I am also grateful to the anonymous reviewers for their helpful and generous feedback. Work on this paper was carried out during a period of research funded by the Templeton Religion Trust. The opinions expressed here are those of the author and do not necessarily reflect the views of the Templeton Religion Trust.

Open Access This article is licensed under a Creative Commons Attribution 4.0 International License, which permits use, sharing, adaptation, distribution and reproduction in any medium or format, as long as you give appropriate credit to the original author(s) and the source, provide a link to the Creative Commons licence, and indicate if changes were made. The images or other third party material in this article are included in the article's Creative Commons licence, unless indicated otherwise in a credit line to the material. If material is not included in the article's Creative Commons licence and your intended use is not permitted by statutory regulation or exceeds the permitted use, you will need to obtain permission directly from the copyright holder. To view a copy of this licence, visit http://creativecommons.org/licen ses/by/4.0/.

\section{References}

Annas, J. (2011). Intelligent virtue. Oxford University Press.

Aristotle (trans. Ross). (1998). The Nicomachean ethics. Oxford University Press.

Badhwar, N. (1996). The limited unity of virtue. Noûs, 30(3), 306-329.

Baehr, J. (2011). The inquiring mind. Oxford University Press.

Baril, A. (2013). Pragmatic encroachment in accounts of epistemic excellence. Synthese, 190(17), 3929-3952.

Battaly, H. (2015). Virtue. Polity Press.

Battaly, H. (2017). Intellectual perseverance. Journal of Moral Philosophy, 14(6), 669-697.

Battaly, H. (2019). A third kind of intellectual virtue. In H. Battaly (Ed.), The Routledge handbook of virtue epistemology (pp. 115-126). Routledge. 
Battaly, H. (2020). Closed-mindedness and arrogance. In A. Tanesini \& M. P. Lynch (Eds.), Polarization, arrogance, and dogmatism (pp. 53-70). Routledge.

Brickhouse, T., \& Smith, N. (1997). Socrates and the unity of the virtues. The Journal of Ethics, 1(4), 311-324.

Cooper, J. (1998). The unity of virtue. Social Philosophy and Policy, 15(1), 233-274.

Devereux, D. (1992). The unity of the virtues in Plato's Protagoras and Laches. The Philosophical Review, 101(4), 765-789.

Driver, J. (2001). Uneasy virtue. Cambridge University Press.

Fieser, J. (1998). Hume's wide view of the virtues. Hume Studies, 24(2), 295-311.

Hursthouse, R. (1999). On virtue ethics. Oxford University Press.

Hursthouse, R. (2006). Practical wisdom: A mundane account. Proceedings of the Aristotelian Society, 106(1), 285-309.

Penner, T. (1973). The unity of virtue. The Philosophical Review, 82(1), 35-68.

Plato (trans. Jowett). (1955). Protagoras. In R. Demos (Ed.), Plato selections (pp. 51-105). Charles Scribner's Sons.

Plato (trans. Sprague). (1997). Laches. In J. Cooper (Ed.), Plato: Complete works (pp. 664-686). Hackett Publishing.

Roberts, R., \& Wood, J. (2007). Intellectual virtues. Oxford University Press.

Russell, D. (2009). Practical intelligence and the virtues. Oxford University Press.

Toner, C. (2014). Full unity of the virtues. The Journal of Ethics, 18(3), 207-227.

Vlastos, G. (1972). The unity of the virtues in 'Protagoras.' The Review of Metaphysics, 25(3), $415-458$.

Watson, G. (1984). Virtues in excess. Philosophical Studies, 46(1), 57-74.

Williams, B. (1985). Ethics and the limits of philosophy. Harvard University Press.

Wolf, S. (2007). Moral psychology and the unity of the virtues. Ratio, 20(2), 145-167.

Zagzebski, L. T. (1996). Virtues of the mind. Cambridge University Press.

Publisher's Note Springer Nature remains neutral with regard to jurisdictional claims in published maps and institutional affiliations. 